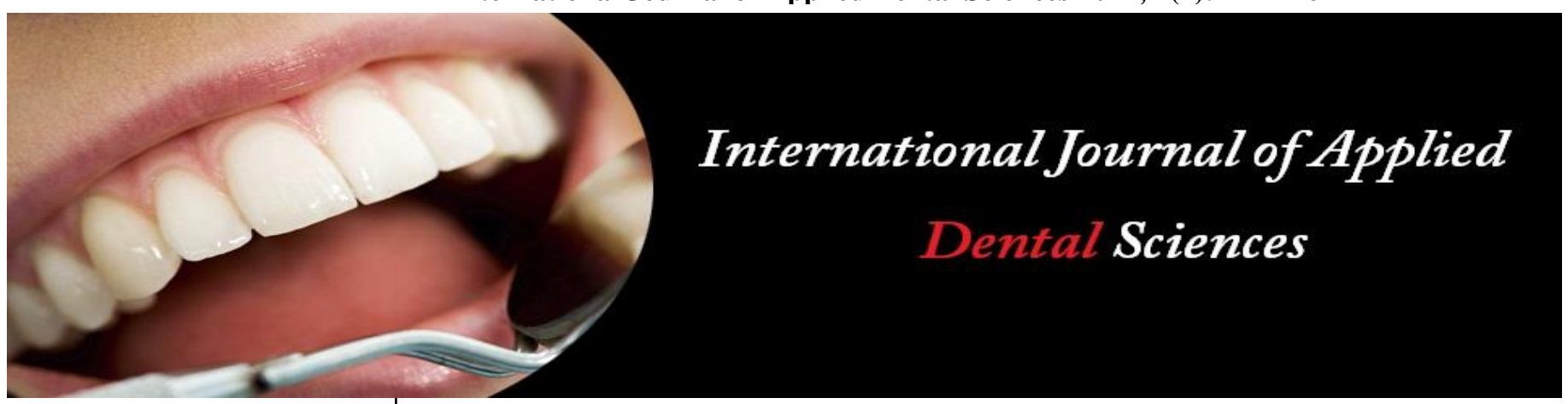

ISSN Print: 2394-7489

ISSN Online: 2394-7497

IJADS 2021; 7(2): 244-246

(C) 2021 IJADS

www.oraljournal.com

Received: 29-01-2021

Accepted: 17-03-2021

Dr. Kanchan Bhagat

MDS in Conservative Dentistry

and Endodontics,

Designation- Dental Surgeon,

Indira Gandhi Govt. Dental

College and Hospital, Jammu,

India

Dr. Ankush Jasrotia

MDS in Conservative Dentistry and Endodontics,

Designation- Dental Surgeon, Govt. SDH Hospital Akhnoor,

Jammu, India

Dr. Ravinder Kumar Bhagat MDS in Conservative Dentistry and Endodontics

Designation- Dental Surgeon School Health Scheme, CMO Office, Reasi, Jammu, India

Corresponding Author: Dr. Ankush Jasrotia MDS in Conservative Dentistry and Endodontics,

Designation- Dental Surgeon, Govt. SDH Hospital Akhnoor, Jammu, India

\section{A comparison of cold lateral compaction and warm vertical compaction using continuous wave of compaction technique}

\author{
Dr. Kanchan Bhagat, Dr. Ankush Jasrotia and Dr. Ravinder Kumar \\ Bhagat
}

DOI: https://doi.org/10.22271/oral.2021.v7.i2d.1216

\section{Abstract}

Background: Variety of techniques are used to obturate the root-canal system, which can be divided into two basic groups: cold lateral compaction or warm vertical compaction. The present study was conducted to compare cold lateral compaction and warm vertical compaction using continuous wave of compaction technique.

Materials \& Methods: 30 simulated, 30-degree, curved root canals in transparent acrylic blocks were divided into group I and II. In group I, cold lateral compaction was performed. In group II, warm vertical compaction was used.

Results: Group I and group II, mean weight of instrumented block was 3.80 gram each, mean weight of obturated block was 3.86 gram and 3.88 gram and mean weight of gutta-percha was 0.042 and 0.56 respectively. The difference was significant $(\mathrm{P}<0.05)$

Conclusion: Warm vertical compaction using the continuous wave of compaction technique in acrylic blocks resulted in a greater gutta percha fill by weight in comparison to cold lateral compaction.

Keywords: Continuous wave, Lateral compaction, Warm vertical compaction

\section{Introduction}

The main objectives of endodontic therapy are cleaning and shaping, disinfection, and obturation of the root-canal system in three dimensions ${ }^{[1]}$. Gutta-percha is the most widely used and accepted obturation material because of its biocompatibility, inertness, dimensional stability, compactability, plasticity when heated, and ease of removal for post placement or retreatment. Sealing the root canal system is an important step in root canal treatment for a successful outcome ${ }^{[2]}$. Several techniques and materials have been introduced for a threedimensional obturation with higher density and homogeneity. Void-free filled canals carry a lower risk of apical periodontitis. Gutta-percha has long been used as a popular root filling material. The chemical and physical properties of gutta percha enable its application in several obturation techniques ${ }^{[3]}$.

Variety of techniques are used to obturate the root-canal system, which can be divided into two basic groups: cold lateral compaction or warm vertical compaction. Lateral compaction offers the advantage of controlled placement of gutta-percha into the root canal, but the obturation is time consuming, lacks homogeneity with spaces formed between cones, poorly adapts to the canal walls, and may induce vertical root fractures ${ }^{[4]}$. Vertical compaction uses heat to produce a homogenous obturation that adapts well to the canal walls. This technique may result in the extrusion of gutta-percha into the periapical tissues and may be time consuming ${ }^{[5]}$. Because of the disadvantages of these techniques, several variations have been developed. Many have evolved to decrease operating time, take advantage of the benefits of the warm gutta-percha technique, and gain better apical control of the gutta-percha ${ }^{[6]}$. The present study was conducted to compare warm vertical compaction and cold lateral compaction using continuous wave of condensation technique. 
pumice powder (neelkanth healthcare pvt. ltd.).

\section{Materials \& Methods}

The present study comprised of 30 simulated, 30-degree, curved root canals in transparent acrylic blocks instrumented with One Curve \#25.06 (Micro-MegaSA, France) taper nickel-titanium rotary files using a crown-down technique. Determination of working length was performed by placing a a size 15 no. K-file (Dentsply Maillefer, Ballaigues Switzerland) into the canal until it was visible at the apical foramen. The working length was determined by subtracting $1 \mathrm{~mm}$ from this measurement. The apical portion of each canal was prepared to One Curve \#25.06. Patency was maintained by passing a 10 no. K-file to the apical foramen after the use of each rotary file. The canal was irrigated with $1 \mathrm{ml}$ of water between each instrument use, and on completion the canal was dried with paper points. The blocks were divided into group I and II. Each block was weighed to the nearest $0.001 \mathrm{~g}$ using a digital balance. In group I, a standardized \#25 guttapercha cone was placed to working length without sealer. A spreader was inserted into the canal to within $1 \mathrm{~mm}$ of the working length, and cold lateral compaction was performed. In group II, a 0.06 taper gutta-percha point was placed to working length without sealer. Element obturation unit (Orange California, USA), was used for warm vertical compaction by continuos wave of compaction. A fine heat Buchanan plugger of size 0.06 in System B, was introduced into the canal $5 \mathrm{~mm}$ short of working length to capture a wave of compaction pressure at the orifice of a canal and ride it, without release, to the apical extent of the downpack in a single, continuous movement. The remainder of the canal is then filled with the backfill by the extruder of Element Obturation unit. Data obtained were subjected to statistical analysis. $\mathrm{P}$ value less than 0.05 was considered significant.

\section{Results}

Table 1: Distribution of blocks

\begin{tabular}{|c|c|c|}
\hline Groups & Group I & Group II \\
\hline Method & Cold lateral compaction & Warm vertical compaction \\
\hline Number & 15 & 15 \\
\hline
\end{tabular}

Table I shows that in group I, cold lateral compaction and in group II warm vertical compaction technique was used. Each group had 15 blocks.

Table II: Comparison of gutta-percha weight

\begin{tabular}{|c|c|c|c|}
\hline Parameters & Group I & Group II & P value \\
\hline $\begin{array}{c}\text { Mean weight of instrumented } \\
\text { block (g) }\end{array}$ & 3.80 & 3.80 & 1 \\
\hline $\begin{array}{c}\text { Mean weight of obturated } \\
\text { block (g) }\end{array}$ & 3.86 & 3.88 & 0.92 \\
\hline Mean weight of gutta-percha & 0.042 & 0.56 & 0.01 \\
\hline
\end{tabular}

Table II, graph I shows that group I and group II, mean weight of instrumented block was 3.80 gram each, mean weight of obturated block was 3.86 gram and 3.88 gram and mean weight of gutta-percha was 0.042 and 0.56 respectively. The difference was significant $(\mathrm{P}<0.05)$

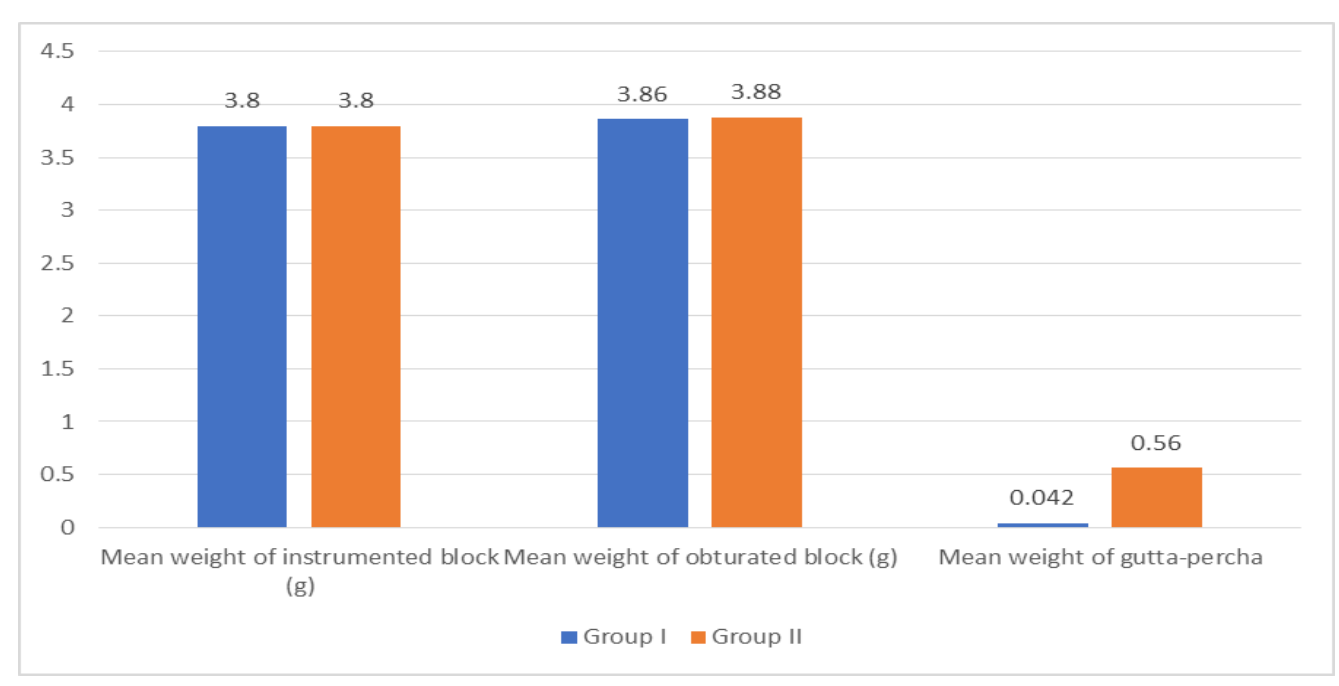

Graph 1: Comparison of gutta-percha weight

\section{Discussion}

Cold LC is a successful technique due to its simplicity, not requiring specific and expensive instruments and low cost ${ }^{[7]}$. Disadvantages of this technique include risk of void formation, inadequate adaptation of root filling material to the root canal walls and partial filling in certain hard-to-reach areas of the root canal system ${ }^{[8]}$. The main advantages of thermoplasticized gutta percha techniques include better adaptation to root canal complexities, lower risk of void formation and creating a dense filling ${ }^{[9]}$. The present study was conducted to compare cold lateral compaction and warm vertical compaction using continuous wave of compaction technique.

In present study, in group I, cold lateral compaction and in group II warm vertical compaction technique was used. Each group had 15 blocks. Lea et al ${ }^{[10]}$ in their study group A was obturated with the cold lateral-compaction technique using medium fine, gutta-percha accessory points until the canal was completely filled. Group B was obturated with the continuous wave of condensation technique until the canal was completely filled. The blocks were weighed again after obturation. Results demonstrated that the continuous wave of condensation technique resulted in a significantly greater density compared with cold lateral compaction. Warm vertical compaction using the continuous wave of compaction technique in acrylic blocks resulted in a greater gutta percha fill by weight compared with standard cold lateral compaction.

We found that group I and group II, mean weight of instrumented block was 3.80 gram each, mean weight of 
obturated block was 3.86 gram and 3.88 gram and mean weight of gutta-percha was 0.042 and 0.56 respectively.

Aminsobhani et al ${ }^{[11]}$ introduced modified continuous wave compaction (MCWC) technique and compared its obturation quality with that of lateral compaction (LC), warm vertical compaction (WVC) and continuous wave compaction techniques (CWC). Sixty-four single-rooted teeth with $0-5^{\circ}$ root canal curve and 64 artificially created root canals with $15^{\circ}$ curves in acrylic blocks were evaluated. The teeth and acrylic specimens were each divided into four subgroups of 16 for testing the obturation quality of four techniques namely LC, WVC, CWC and MCWC. Canals were prepared using the Mtwo rotary system and filled with respect to their group allocation. Obturation time was recorded. No significant difference existed in adaptation of filling materials to canal walls among the four subgroups in teeth samples $(P \geq 0.139)$; but, in artificially created canals in acrylic blocks, the frequency of areas not adapted to the canal walls was significantly higher in LC technique compared to MCWC (P $\leq 0.02)$. The void areas were significantly more in the LC technique than in other techniques in teeth $(\mathrm{P}<0.001)$. The longest obturation time belonged to WVC technique followed by $\mathrm{LC}, \mathrm{CW}$ and MCWC techniques.

Liewehr et al ${ }^{[12]}$ used clear acrylic blocks to compare the density of standard cold lateral compaction followed by warm lateral compaction with the Endotec thermal endodontic condenser. The blocks were weighed after instrumentation, and after cold or warm lateral compaction techniques. An increase in the final weight of the filling material in the same volume implied an increase in density of the obturation.

\section{Conclusion}

Authors found that warm vertical compaction using the continuous wave of compaction technique in acrylic blocks resulted in a greater gutta percha fill by weight compared with standard cold lateral compaction.

\section{References}

1. Weller RN, Kimbrough WF, Anderson RW. A comparison of thermoplastic techniques: adaptation to the canal walls. J Endod 1997;23:703-6.

2. Holcomb J, Pitts D, Nicholls J. Further investigation of spreader loads required to cause vertical root fracture during lateral condensation. J Endod 1987;13:277-84.

3. Lertchirakarn V, Palamara JEA, Messer HH. Load and strain during lateral condensation and vertical root fracture. J Endod 1999;25:99 -104.

4. Wu MK, Kast'akova A, Wesselink PR. Quality of cold and warm gutta-percha in oval canals in mandibular premolars. J Endod 1998;24:223- 8.

5. Budd CS, Weller RN, Kulild JC. A comparison of the rmoplasticized injectable gutta-percha obturation techniques. J Endod 1991;17:260 - 4.

6. Buchanan LS. The continuous wave of condensation technique: a convergence of conceptual and procedural advances in obturation. Dent Today 1994;13:80.

7. Sweatman T, Baumgartner J, Sakguichi R. Radicular temperatures associated with thermoplasticized guttapercha. J Endod 2001;27:512-5.

8. Floren JW, Weller RN, Pashley DH, Kimbrough WF. Changes in root surface temperatures with in vitro use of the System B Heatsource. J Endod 1999;25:593-5.

9. Bowman C, Baumgartner J. Gutta-percha obturation of lateral grooves and depressions. J Endod 2002;28:220 -3.

10. Lea CS, Apicella MJ, Mines P, Yancich PP, Parker MH.
Comparison of the obturation density of cold lateral compaction versus warm vertical compaction using the continuous wave of condensation technique. Journal of endodontics 2005;31(1):37-9.

11. Aminsobhani M, Ghorbanzadeh A, Sharifian MR, Namjou S, Kharazifard MJ. Comparison of obturation quality in modified continuous wave compaction, continuous wave compaction, lateral compaction and warm vertical compaction techniques. Journal of Dentistry (Tehran, Iran) 2015;12(2):99.

12. Liewehr FR, Kulild JC, Primack PD. Improved density of gutta-percha after warm lateral condensation. J Endod 1993;19:489-91. 